\title{
A Bibliographic Review of Literature on Machine Accidents Published in the Journals Indexed with Scopus-Elsevier Database from 2019 - 1972
}

\author{
Javed Rasool Khara ${ }^{1 *}$, Zameer Hussain Baladi ${ }^{2}$
}

${ }^{1}$ Health, Safety \& Environment Manager, Rayan Plastic Factory, Co, Riyadh Kingdom of Saudi Arabia

${ }^{2}$ King Saud Bin Abdulaziz University for Health Sciences, College of Applied Medical Sciences, Riyadh, Kingdom of Saudi Arabia

DOI: $10.36347 /$ sjet.2020.v08i11.001

| Received: 16.10.2020 | Accepted: 30.10.2020 | Published: 06.11.2020

*Corresponding author: Javed Rasool Khara

Abstract Original Research Article

Purpose: This study design explores the literature produced and published in journals indexed in the Scopus-Elsevier database in terms of machine accidents. Methods: We acquired support from the Scopus-Elsevier information base and its listed journals to download the information for this examination. The data covers 48 years of exploration. This examination is separated into five spells to analyze; year-wise, sort of reports, an arrangement of subjects, creators design transport, an association of the primary creator with the nation, and dialects of a composition, distributed from 2019 - 1972. Results: One hundred forty-six different types of documents were written by $395 ; 2.7 \%$ authors in eleven languages and categories in eleven subject areas published in the Scopus-Elsevier database from 2019- 1972. Majority of $81 ; 55 \%$ documents scripted as articles, followed by conference papers. The first spell published $84 ; 57 \%$, remaining 62; $42.4 \%$ documents published in four spells. With 47 documents, Industrial Engineering got maximum attention, Road, and Traffic with 46 documents, and Agricultural and Biological Sciences with 17documents and stand on second and third. The majority $102 ; 69.8 \%$ of documents written in collaboration, and $44 ; 30.1 \%$ documents scripted by single or solo authors. Out of 146 papers, the literature $(85 ; 58.2 \%)$ of papers published by five countries, and the remaining $61 ; 41.7 \%$ documents contributed by 26 countries out of 31 countries. Conclusion: Education has power to move society towards science and technology. This study revealed that, the ultimate goal of library professionals is to save the time of reading through the ease of system with educational programs, instead of this the subject got lase attention among the eyes of library professionals.

Keywords: Bibliometric, machine accidents, accident preventions, risk assessments, machine learnings, automation.

Copyright $(\mathbf{2 0 2 0}$ The Author(s): This is an open-access article distributed under the terms of the Creative Commons Attribution 4.0 International License (CC BY-NC 4.0) which permits unrestricted use, distribution, and reproduction in any medium for non-commercial use provided the original author and source are credited.

\section{INTRODUCTION}

Machine, a mechanical gadget, utilizes the ability to apply powers to force and control movement to perform an intended action and this control development to play out an expected activity 1 . Machines can be driven by individuals for ordinary powers, such as wind and water, and by synthetic, warm, or electrical force, and incorporate an arrangement of systems that shape the actuator contribution to accomplish a particular utilization of yield powers development 2[12]. Current machines are unpredictable frameworks comprising essential components, techniques, and control segments and incorporate interfaces for advantageous use. Models include a broad scope of vehicles, for example, cars, pontoons, and planes, apparatuses in the home and office, including PCs, building air taking care of and water taking care of frameworks, just as ranch hardware, machine devices, and industrial facility computerization frameworks and robots 3 .

An accident is a spontaneous occasion that occasionally has poorly designed or unfortunate results, different experiences being insignificant. The event of such an incident might have unrecognized or unaddressed dangers adding to its motivation 4. Most researchers who study unexpected injury abstain from utilizing the expression "mishap" and spotlight factors that expand the threat of severe injury and decrease injury occurrence and seriousness 5 . Indeed, physical instances of mishaps incorporate unintended engine vehicle crashes or falls, harmed by contacting something sharp, hot, dropping a plate, coincidentally kicking the leg of a seat while strolling, unexpectedly 
keeping quiet while eating, incidentally tipping over a glass of water, reaching power or ingesting poison 6.

Non-physical models are inadvertently uncovering a mystery or, in any case, saying something erroneously, unexpected cancellation of information, overlooking an arrangement, and so on 7. For avoiding these misshapes, risk managers amply various operational and financing procedures with identification of accidents, gauge the sort of loss and curtail the portion of disaster with the submission of effective management among the human, financial, technical, and informative resources 8 . Risk management policies, developed by sound organizations towards play a critical practice to switch the difficulties and ascends sufficiently can change the cause, shape, and harms to growth 9.

Urbański, M et al. [1] measured that project planning needed a statistically significant influence on project success in any business. The determination of that assessment contributes to improving the figure of information intended for global companies and academicians aiming to implement risk management contexts to enhance project success and guarantee the effectiveness of project planning in a corporate environment 10. Ketha, T., Imambi, S.S [2], analysis and found road accidents affected the nation's wellbeing and economy. They mentioned the report of WHO that an individual's of the world dies in millions every year. They suggested that the transport regulatory bodies make and execute safe driving proposals 11 . Indeed, before Ketha, T., Fan, Z., et al. [2] from the School of Earth Sciences and Engineering, Hohai University, China identified black spots in urban traffic accident safety in his research based on traffic accident data of Suzhou Industrial Park. They suggested that a dynamic machine-learning algorithm based on a neural network can specify the factors of accidents; time, space, increase number of vehicles, roads, condition of vehicles, and people are the most productive factors 12 .

Surprisingly, Lee, Y., et al. [3] closest to Fan, $\mathrm{Z}$., [10, 11] and proposed a similar prediction model with modification of Linear Discriminant Analysis (LDA) to check the grade of injuries and automatic traffic accident notifications system from the machinelearning algorithm, which supports logistic regression and vector machine 13. Simultaneously, Vladkove, B. [9], expanded the nomenclature of accidents; he elaborated that; electric stuns, moving hefty stacked hardware, slip and outings, ignorance about the utilization of appropriate individual defensive equipment, and helpless working conditions are the blended appearances of wellbeing and security in development industry 14. Vigneshkumar, C. [4], conducted a study on fall from high (FFH); he states that developing examination territories in the expansion businesses, in a setting; personal computer and data innovation apparatuses help assess existing wellbeing the executive's programs in avoidance of harms and misfortunes 15. Expectedly, Wang, B. et al. [8] proclaimed that safety science comes in new and broader shape in China. A viable wellbeing and security the executive's framework sets up and keeps up a security culture that pervades the whole association. Guaranteeing wellbeing on building destinations is a significant challenge regarding the board responsibility with fulfilling time constraints between business-related mishaps and business-related infections 16 .

Much before Wang, Fuller, C. W. [5] insisted on taking care of assets and human beings' safety. The executives' health and security are fundamental in the development and establishment regions for big business supportability, worker wellbeing, and social soundness 17. Furthermore, Di Donato et al. [7] saw it with another angle that; the likely damage to laborers, a genuine mishap can make work halted or postponed and lead to abatement in profitability because of low assurance 18. Beside, Di Donato, Veil, S.R., et al.[6] draw the big picture of losses that, notwithstanding affiliation size or type, the best prosperity and security the chiefs structures apply a decision making ability approach subject to a thorough perception of the specific threats and risks the association faces step by step 19.

\section{DESIGN/METHODS/APPROACH}

This retrospective study examines the published documents on machine accidents as "Article title" in journals indexed with the Scopus-Elsevier database from 2019 - 1972 (48 years). Data distributed in five spells accorded to years for examining; year wise frequency of publication, type of documents, primary classification of subjects, authors' contribution, an affiliation of the first author with country, languages of the manuscripts.

\section{RESULTS}

Figure 1, and table 1, explains that the 146 documents published on the machine accidents from 2019 - 1972 in journals indexed with the ScopusElsevier database with an average $29.2 \%$ of documents per decade. Ten languages utilized in scripted these publications; English 118, German, 9, Chinese 6, French 2, Italian, Danish, Korean, Polish, Russian, Slovak, and Turkish one manuscript written in these languages. Table 1 shows the breakdown of records in five spells. Articles got the first slot in every period and produced 84; 57.5\% documents. Stones, M., produced four articles. 

Scopus-Elsevier Database from 2019 - 1972

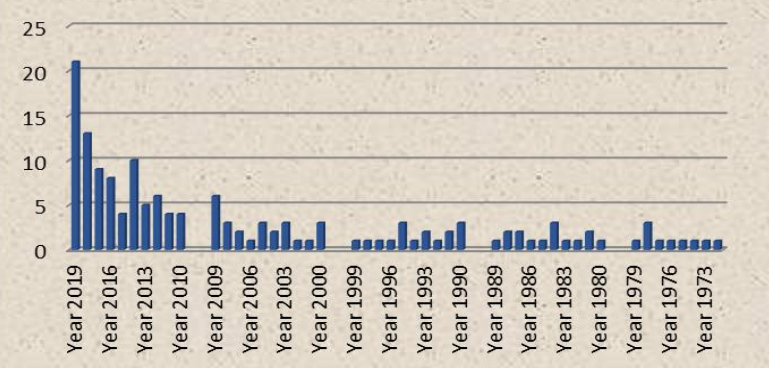

Table-1: Documents published in Scopus-Elsevier database on machine accidents from 2019 - 1972 separated in five spells.

\begin{tabular}{|l|l|l|}
\hline S. No & Spells & Published documents \\
\hline 1 & $2019-2010$ & $84(57.5 \%)$ \\
\hline 2 & $2009-2000$ & $21(14.3 \%)$ \\
\hline 3 & $1999-1990$ & $13(9 \%)$ \\
\hline 4 & $1989-1980$ & $8(5.4 \%)$ \\
\hline 5 & $1979-1972$ & $20(13.7 \%)$ \\
\hline Total & 146 \\
\hline
\end{tabular}

Figure 2 displays the types of documents; 81 articles, 55 conference papers, 6 notes, 2 review articles, 1 book chapter, and 1 letter published on machine accidents from 2019 - 1972.

Figure 2: Types of documents on machine accidents published in Scopus-Elsevier Database from 2019 - 1972

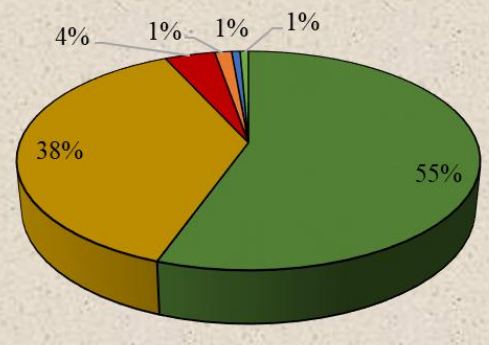

口Article

口Conference Paper

DNote

口Review

口Book Chapter

口Letter
Figure 3 is an essential part of this study; literature published on machine accidents is divided into eleven categories to understand. We set this data according to John Dewey compiles library classification schemes. Results showed that the writings associated with Industrial Engineering got maximum attention due to utilization of heavy machinery and Road and Traffic with a second, and Agricultural and Biological Sciences as third.

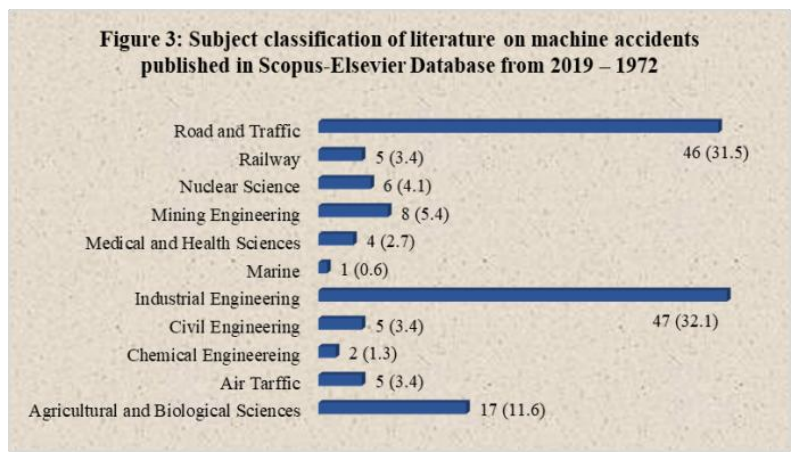

Figure 4 and table 2 describes the interest of scholar in writing. The author intended to say, share and convince other authors on and about the same sky. In this study, the participation of single-author $75 \%$ is mammoth, followed by two authors as in collaborative manners.

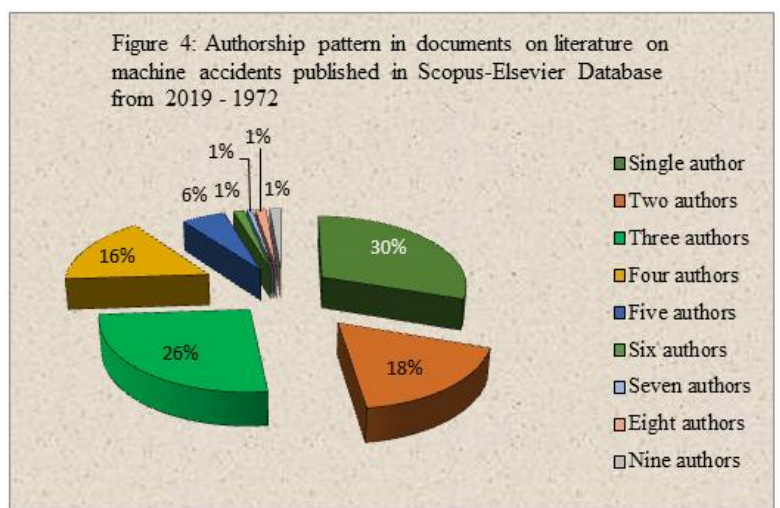

Table-2: Pattern of authorship in documents published in Scopus-Elsevier database machine accidents from 2019 - 1972.

\begin{tabular}{|l|l|l|l|l|l|l|l|l|}
\hline S. No & Authorship pattern & $\begin{array}{l}\mathbf{2 0 1 9} \\
\text { To } \\
\mathbf{2 0 1 0}\end{array}$ & $\begin{array}{l}\mathbf{2 0 0 9} \\
\text { to } \\
\mathbf{2 0 0 0}\end{array}$ & $\begin{array}{l}\mathbf{1 9 9 9} \\
\text { to } \\
\mathbf{1 9 9 0}\end{array}$ & $\begin{array}{l}\mathbf{1 9 8 9} \\
\text { to } \\
\mathbf{1 9 8 0}\end{array}$ & $\begin{array}{l}\mathbf{1 9 7 9} \\
\text { to } \\
\mathbf{1 9 7 2}\end{array}$ & Authors & Total authors \\
\hline 1 & Single author & 15 & 6 & 3 & 4 & 16 & 44 & 44 \\
\hline 2 & Two authors & 11 & 2 & 6 & 3 & 4 & 26 & 52 \\
\hline 3 & Three authors & 25 & 10 & 2 & 1 & & 38 & 114 \\
\hline 4 & Four authors & 19 & 3 & 1 & & & 23 & 92 \\
\hline 5 & Five authors & 7 & & 1 & & & 8 & 40 \\
\hline 6 & Six authors & 2 & & & & & 2 & 12 \\
\hline 7 & Seven authors & 1 & & & & & 1 & 7 \\
\hline 8 & Eight authors & 2 & & & & & 2 & 16 \\
\hline 9 & Nine authors & 2 & & & & & 2 & 18 \\
\hline & Total & 84 & 21 & 13 & 8 & 20 & 146 & 395 \\
\hline
\end{tabular}


Table 3 highlighted the importance of the severity of machine accidents; the association of 31 countries reveals that this topic has significance with other similar issues.

Five countries published the majority 85 ; $58.2 \%$ documents, and the remaining $61 ; 41.7 \%$ documents contributed by 26 countries. The other participatory names of hidden countries are France and
South Korea, present seven papers each. Brazil, United Kingdom, Poland, and Turkey contributed five articles each. Italy 3, Czech Republic, Greece, Iran, Spain, and Sweden participated in collaboration with two papers. Austria, Bangladesh, Chile, Egypt, Mexico, New Zealand, Norway, Oman, Romania, Russian Federation, Serbia, Estonia, Taiwan, and United Arab Emirates present their contribution with one document.

Table-3: Participation of countries in documents Published in Scopus-Elsevier database on machine accidents from $2019-1972$

\begin{tabular}{|l|l|l|l|}
\hline S. No & & Documents & \% \\
\hline 1 & China & 31 & $21.2 \%$ \\
\hline 2 & United States of America & 26 & $17.8 \%$ \\
\hline 3 & Germany & 10 & $6.8 \%$ \\
\hline 4 & India & 10 & $6.8 \%$ \\
\hline 5 & Japan & 8 & $5.4 \%$ \\
\hline 6 & 02 countries participates in 7 documents & 14 & $9.5 \%$ \\
\hline 7 & 04 countries participates in 5 documents & 20 & $13.7 \%$ \\
\hline 8 & 01 country participates in 3 documents & 3 & $2 \%$ \\
\hline 9 & 05 countries participates in 2 documents & 10 & $6.8 \%$ \\
\hline 10 & 14 countries participates in 1 document & 14 & $9.5 \%$ \\
\hline Total & & 146 & \\
\hline
\end{tabular}

\section{DISCUSSION \& CONCLUSION}

According to Dewey Decimal Scheme (DDC), the word philosophy pertained in Philosophy and Psychology as numerical $100-190$. This study specifies that $77 \%$ of the literature was published in Social Sciences 300 - 390, followed by Science $500-$ 590, 14 percent. Meanwhile, ten types of documents indicate that most $985,60 \%$ of records published in the last two spells. It is also interesting that 520; $48.5 \%$ articles published in these spells out of 1070 articles, the remaining $550,51.4 \%$ articles produced in six spells. In the last spell, 636 documents published, one document published on every fifth day, instead of one article created on every ninth day of the last spell.

Every document has a writer. This study reveals that $1189,75 \%$ of the solo or single author's documents written out of the 1587 document. A total of 697 journals and publishers provide spaces for publishing these documents, interestingly 518; $32.6 \%$ documents published in 13 places, 564; $35.5 \%$ documents got spaces from 179 locations, and 505; $31.8 \%$ documents produced by 505 sites out of 697 places. Total 68 countries contributed 1587 documents, 22 countries out of 68 produced $1445 ; 91 \%$ documents and 46 states had credit $142 ; 9 \%$ documents.

This study highlighted that education is not a simple work to think, plan, and execute. Every thought, subject, the discipline required the mode of communications to explain the terminology of actions. In conclusion, the study found that abilities and instinct of human polished by education, and this spiritual substance work as a medium to rethink with a philosophical way to contribute individually and society as a whole.

\section{Disclaimer}

This data published in Scopus-Elsevier Database indexed journals from 1929 to 31 December 2019, and downloaded 2 July 2020 for estimation.

\section{REFERENCES}

1. Urbański M, Haque AU, Oino I. The moderating role of risk management in project planning and project success: evidence from construction businesses of Pakistan and the UK. Engineering Management in Production and Services. 2019 Apr 24;11(1):23-35

2. Sulaiman NA, Shaharudin SM, Zainuddin NH, Najib SA. Improving Support Vector Machine Rainfall Classification Accuracy based on Kernel Parameters Optimization for Statistical Downscaling Approach. International Journal. 2020;9(1.4).

3. Lee Y, Cho E, Yoon C, Park S. A study on prediction of passenger's injury grade using public traffic accident database and machine learning. Transactions of the Korean Institute of Electrical Engineers. 2019; 68(7), 866-871.

4. Vigneshkumar C, Salve UR. A scientometric analysis and review of fall from height research in construction. Construction Economics and Building. 2020;20(1):17.

5. Fuller CW. An employee- management consensus approach to continuous improvement in safety management. Employee Relations. 1999 Aug 1. 
6. Veil SR, Anthony KE, Sellnow TL, Staricek N, Young LE, Cupp P. Revisiting the best practices in risk and crisis communication: A multi- case analysis. The Handbook of Applied Communication Research. 2020 Apr 17:377-96.

7. Di Donato MF, Iles R, Lane TJ, Buchbinder R, Collie A. The Impact of Income Support Systems on Healthcare Quality and Functional Capacity in Workers with Low Back Pain: A Realist Review. medRxiv. 2020 Jan 1.

8. Wang B, Wu C, Huang L, Kang L, Lei Y. Safety science as a new discipline in China. Safety science. 2020 Jan 1;121:201-14.

9. Vladkova B. Best practices to improve construction site safety, in the specific conditions of processing plant building. InMATEC Web of Conferences 2020 (Vol. 305, p. 00014). EDP Sciences.
10. Fan Z, Liu C, Cai D, Yue S. Research on black spot identification of safety in urban traffic accidents based on machine learning method. Safety science. 2019 Oct 1; 118:607-16.

11. Fan S, Blanco-Davis E, Yang Z, Zhang J, Yan X. Incorporation of human factors into maritime accident analysis using a data-driven Bayesian network. Reliability Engineering \& System Safety. 2020 Jun 12:107070.

12. Jermsittiparsert K, Nguyen PT, Nguyen QLHTT, Huynh VDB, Shankar K. Challenges in the risk management system for developing a successful business environment [Desafíos en el sistema de gestión de riesgos para desar-rollar un entorno empresarial exitoso] Opcion. 2019; 35(88), 28992921. 